\title{
Crime and genetics conference breeds further controversy
}

Washington. A long-delayed conference on genetics and crime, which finally took place in rural Maryland last weekend, was punctuated by onslaughts from protesters trying to shut it down, and dominated by semantic arguments over words such as 'crime'.

As a result, many participants left the meeting feeling frustrated that it had provided little basis for a substantive debate on the social implications of research in behavioural genetics.

The conference was originally due to have taken place three years ago, but was cancelled when funding from the National Institutes of Health was withdrawn following opposition from the Congressional Black Caucus and others.

Its goal was to provide a forum for discussing both the scientific data and the political implications of work in this field. The organizer of the conference, David Wasserman of the University of Maryland, says that its primary goal was to explore "the social, legal and ethical implications of the current research on genetics and criminal behaviour".

Irving Gottesman of the University of Virginia - an active researcher in twin studies used to detect the genetic basis for human behaviour - tried to set a conciliatory tone for the meeting at the outset by stating that "everyone at the conference could agree that we must fight genetic discrimination".

But the depth of any such common feeling was repeatedly questioned as 35 scientists, criminologists, historians and philosophers each took the floor during the three-day event, held at the Aspen Institute in Queenstown, near Annapolis.

Several researchers insisted that their research was non-racist, for example where it was limited to studies of Caucasians in countries such as Denmark with little racial conflict. But Katheryn Russell, of the University of Maryland's department of criminal justice, said that the implications of even this type of research were "inherently racist", as it was based on a racially biased view of crime.

Indeed, semantics emerged as the dominant theme of the meeting, with lengthy arguments about the meaning and interpretation of words such as 'heritability' and even 'biological'.

The focus on such topics, rather than on behavioural research and its potential dangers, led some participants to question whether the discussions were moving in any productive direction, while expressing frustration at the brevity of the scientific presentations, and inadequate time for questions and answers. Laurie Goodman

\section{Budget kills off US biological service and cuts research}

Washington. The two-year saga of the US National Biological Service (NBS), the controversial agency created by the Interior Secretary, Bruce Babbitt, to focus biological research within the federal government, came to an abrupt end last week.

The House of Representatives and the Senate agreed a budget for the Department of the Interior that abolishes the NBS and transfers its functions to the US Geological Survey (USGS). Funds allotted to "natural resources research" within the USGS next year will be $\$ 137$ million - \$9 million less than the amount proposed by the Senate for the NBS, but $\$ 25$ million more than the figure in the House, where legislators had proposed a merger with USGS earlier this year.

The White House immediately threatened to veto the Interior appropriations bill over items such as logging in Alaska and the Bureau of Indian Affairs. But the NBS is unlikely to figure in any last-minute negotiations between the Congress and the president. Babbitt's plan for a strong and independent ecological research agency which is something the NBS never had the chance to become in its short and turbulent life - therefore appears to have failed.

Exactly how the USGS will absorb the former agency's functions is still to be worked out. The House-Senate committee that made last week's decision instructed the USGS to start dismantling and shrinking the NBS from 1 October, and to report back within nine months on how natural resources research will be integrated into the survey's activities.

Some NBS employees, most of whom were moved from the Fish and Wildlife Service when the new agency was created in
1993, are certain to lose their jobs, as next year's funding level is about 13 per cent lower than this year's. Congress ordered reductions to be made "predominately in administrative, managerial, and other headquarters support functions".

Whether any of the existing NBS centres will have to close is not certain; the Southeast Science Center in Gainesville, Florida, is considered especially vulnerable. Ronald Pulliam, director of the NBS, admitted last week that some continuing long-term studies will have to be scrapped, as will new strategic research.

Indeed, the report accompanying the Interior Department's appropriations bill spells out what kind of "natural resources research" Congress expects the USGS to conduct with its new-found money. The research, it says, should be "closely linked to management issues", implying that it should stick to the kind of work the Fish and Wildlife Service had been doing before NBS was created, such as keeping track of fish and game stocks.

Conservative members of Congress had been sceptical about the NBS from its inception, fearing any wide-ranging ecological surveys would result in more private property being placed off limits to developers.

But one congressional threat to long-term ecological research was removed last week. A Senate amendment prohibiting aerial surveys without written consent of property owners (see Nature 376, 627; 1995) was changed to apply only to surveys "for the designation of habitat under the Endangered Species Act". This should allow work using remote-sensing data to map biological resources to continue.

Tony Reichhardt

\section{NASA prepares for antimatter experiment}

Washington. The US Department of Energy has signed an agreement with the National Aeronautics and Space Administration (NASA) to fly an experiment designed to detect antimatter on the space shuttle and the international space station.

The experiment team for the Alpha Magnetic Spectrometer (AMS), which is made up of scientists from 37 universities and laboratories, is led by Samuel Ting of the Massachusetts Institute of Technology, a joint winner of the 1976 Nobel Prize in physics.

The agreement marks the first time another government agency has sponsored a major experiment on the space station. Daniel Goldin, the NASA Administrator, wasted no time in boasting about Ting's involvement. "I've always said that the space station will be an orbiting laboratory capable of conducting world-class science, and the addition of an experiment whose science team is led by a Nobel laureate is one more step in realizing its full potential."

The heart of the AMS is a cylindrical magnet, one metre in length and one metre in diameter, through which high-energy antimatter particles would pass. The agreement calls for the device to be tested on shuttle mission STS-90 in April 1998, and then to be placed on the space station in 2001 for three years. The project involves collaborators from several countries, including Italy, Switzerland, Germany and China.

DoE will pay $\$ 3$ million for the experiment. NASA is providing $\$ 12.7$ million towards its costs, primarily to pay for integrating the payload into the shuttle and space station. 